\title{
Migrated Disc at Cervicothoracic Junction Presenting as Acute Paraplegia
}

\author{
Amit Mahore ${ }^{1}$, Monit Agarwal ${ }^{1}$, Raghvendra Ramdasi ${ }^{1}$, Vishakha Tikeykar ${ }^{2}$ \\ ${ }^{1}$ Department of Neurosurgery, King Edward Memorial Hospital and Seth Gordhandas Sunderdas Medical College, Mumbai, India \\ ${ }^{2}$ Department of Pathology, Bombay Hospital Institute of Medical Sciences and Research, Mumbai, India
}

Herein, we report on an inferior migration of an intervertebral disc C6-7 to the cervicothoracic junction manifesting as acute paraplegia. The patient showed a remarkable recovery after the surgery. The diagnostic dilemma and management difficulties of such an entity are briefly discussed.

Keywords: Cervical disc prolapse; Disc herniation; Cervico thoracic junction; Disc migration

\section{Introduction}

Herniated discs at the cervicothoracic junction demand attending surgeons to keep eyes open vigilant. A single level disc herniation at the C7-T1 levels is unusual and is often incorrectly diagnosed because of unusual neurological findings and suboptimal imaging studies [1-4]. Herein we present a case of a migrated C6-7 disc causing a spinal cord compression at $\mathrm{C} 7-\mathrm{T} 1$ resulting into an acute compressive myelopathy.

\section{Case Report}

A 70-year-old smoker was admitted with acute onset severe interscapular pain and paraplegia following a bout of cough. The patient was on treatment for coronary artery disease. The clinical examination revealed spatic paraplegia, weak grips with relatively preserved proprioception and sense of vibration. A provisional diagnosis of aortic dissection was made by the emergency physician, but an aortic angiography failed to show any abnormality. The magnetic resonance imaging (MRI) of the spine revealed a midline ventral epidural lesion at $\mathrm{C} 7-\mathrm{T} 1$ level, isointense to cord in both T1 and T2 (Fig. 1A-C). C7-T1 disc space and posterior longitudinal ligament were observed as undisturbed. However, the height of the C6-7 disc was significantly lesser than normal (Fig. 1D) with minimal disc material lying behind the $\mathrm{C} 7$ vertebral body suggestive of a migrated C6-7 disc (Fig. 1B). During operation, the lesion was located in the epidural space of C7-T1. The operation was done using the anterior approach through the $\mathrm{C} 7-\mathrm{T} 1$ disc space. The annulus fibrosus and the posterior longitudinal ligament behind the C7-T1 disc was intact. The diagnosis of the disc material was histologically confirmed (Fig. 2). The patient showed a dramatic and progressive recovery in postoperative period. At 2 years follow-up, the patient had a normal neurological status.

\section{Discussion}

In the cervical spine, most herniated masses penetrate the deep layer of the posterior longitudinal ligament in the

Received May 25, 2014; Revised Jul 3, 2014; Accepted Jul 18, 2014

Corresponding author: Raghvendra Ramdasi

Department of Neurosurgery, King Edward VII Memorial Hospital, Parel, Mumbai-400012, India

Tel: +91-22-24129884, Fax: +91-22-24143435, E-mail: drraghavr@gmail.com 
middle, where the posterior inter vertebral space is widest. Most of the median penetrations end up in paramedian or lateral herniation, whereas paramedian penetrations lead to a lateral herniation through oblique courses. The narrow space of the Luschka joint may prevent fragments from penetrating laterally $[1,4]$. At C7-T1, where there are no Luschka joints, lateral penetration is observed. Thus, a centrally placed and herniated disc mass at C7-T1 remains a rare event and intriguing even whilst considering the possibility of migrated C6-7 disc $[1,4]$.

The compression can involve not only the neural elements themselves, but also the blood vessels that supply
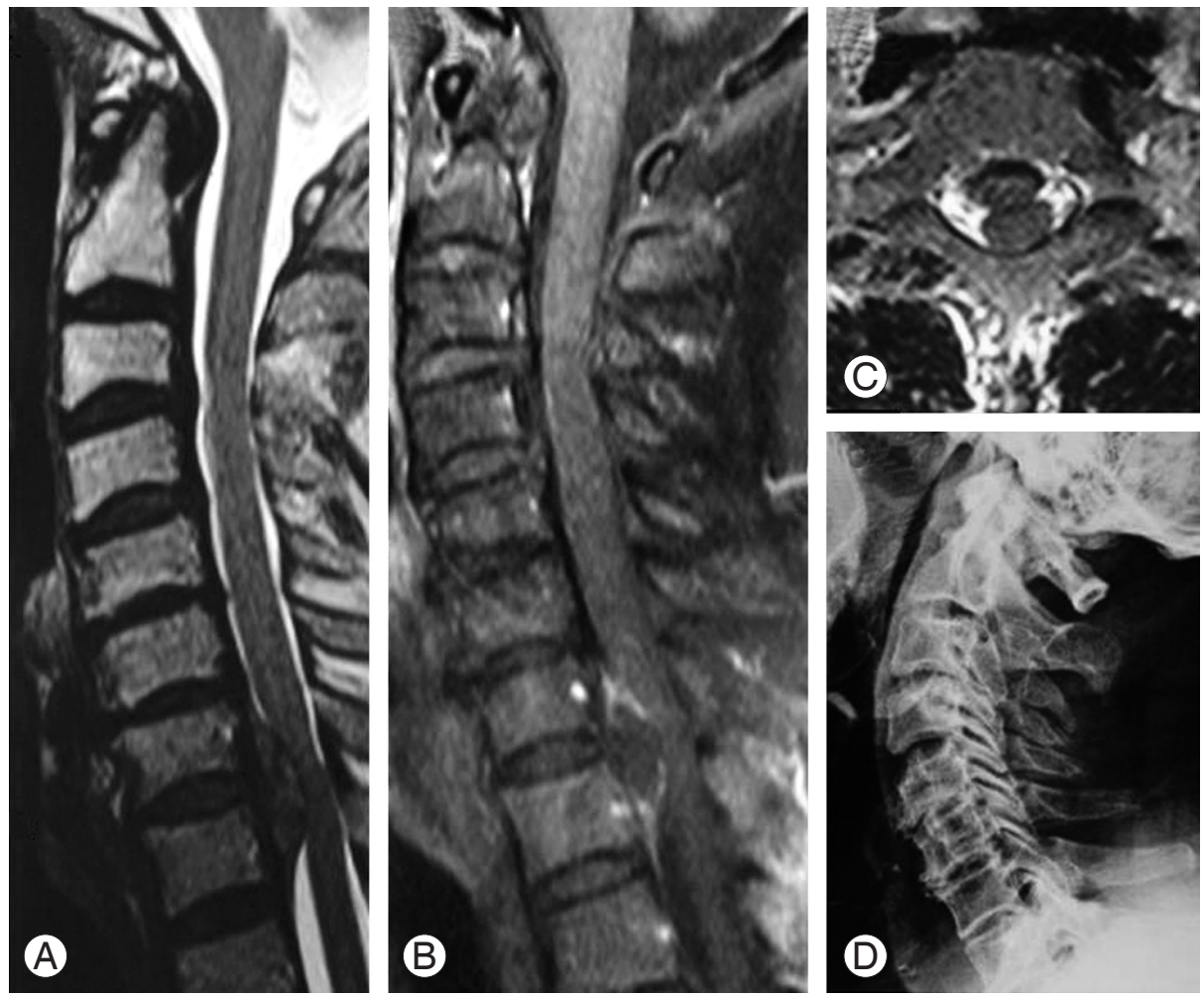

Fig. 1. Magnetic resonance imaging of spine-sagital precontrast T2-weigted (A), post-contrast T1weighted (B), and (C) axial T2-weighted images showing midline ventral epidural lesion behind C7-T1 level with inflammatory reaction and compressive myelopathy. (D) Presents a digital X-ray of the cervical spine showing a normal disc height at the level of $\mathrm{C} 7-\mathrm{T} 1$, whereas the disc space height is reduced at C6-C7 level.
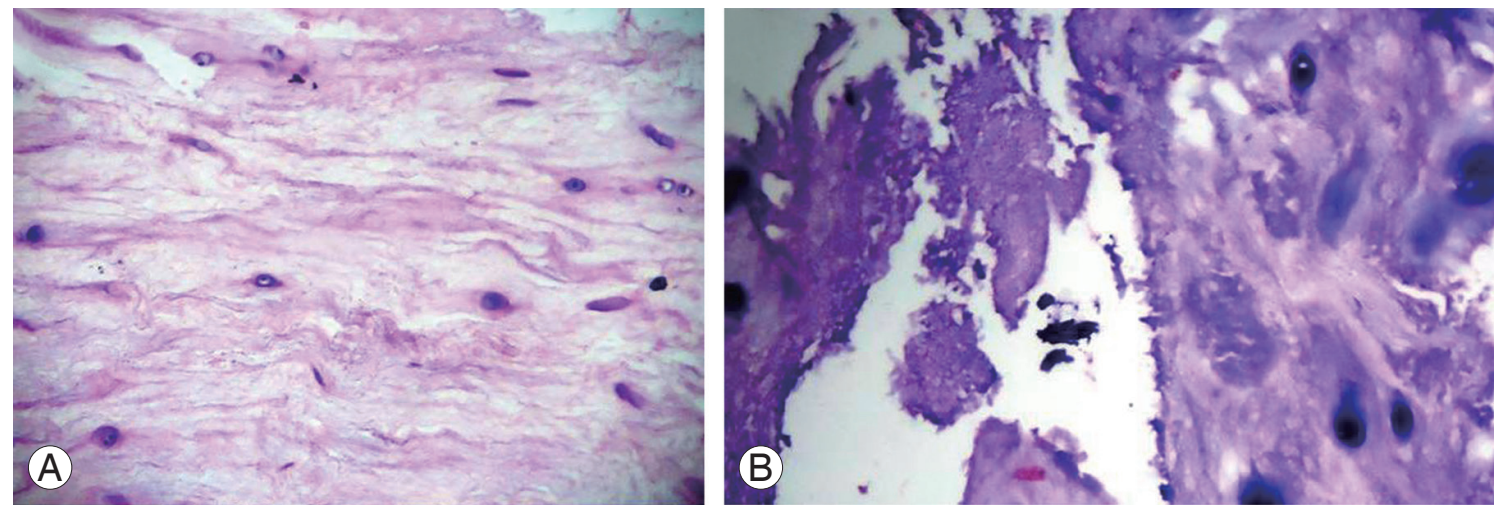

Fig. 2. (A) Photomicrograph $(H \& E, \times 40)$ showing degenerated nucleus pulposus composed of irregualar fibrillar matrix. (B) Photomicrograph $(H \& E, \times 40)$ showing calcification of the cartilage cells and the surrounding matrix. 
them. The most vulnerable vessel is the anterior spinal artery. Patients with a partial spinal cord transaction syndrome are often first thought to have multiple sclerosis or spinal cord tumor until the correct diagnosis is revealed by a MRI and then confirmed at surgery $[1,3,4]$.

Anterior approaches to the cervicothoracic junction are difficult during a spinal surgery because the operative area is narrow. The manubrium, the clavicles and the slope of the vertebral bodies obstruct the view of the surgeon. The vascular and neural structures of the superior mediastinum limit the surgical approach. Posterior approaches are advocated at $\mathrm{C} 7-\mathrm{T} 1$ level as radicular symptoms occur more often than myelopathic symptoms [2]. But an anterior approach is ideal in a central disc prolapse. Understanding the site and characteristic course of the herniation can guide in choosing the approach and thus achieving a complete removal of the herniated mass. Retrospectively, we infer our case as a case of inferiorly migrated C6-7 intervertebral disc causing an anterior cervical cord syndrome.

Our case is of significance for more than one reason. It clearly demonstrates an acutely large migrated cervical disc. Additionally, it emphasizes the fact that it may clinically mimic an aortic dissection in elderly patients if located at the cervicothoracic junction. It also suggests that such patients have an excellent clinical outcome if they were early operated via anterior approach.

A migrated disc at the cervicothoracic junction may be a diagnostic dilemma. The vigilant study of adjacent levels may help to clinch the diagnosis.

\section{Conflict of Interest}

No potential conflict of interest relevant to this article was reported.

\section{References}

1. Manabe S, Tateishi A. Epidural migration of extruded cervical disc and its surgical treatment. Spine (Phila Pa 1976) 1986;11:873-8.

2. Ozer AF, Kaner T, Sasani M, Oktenoglu T, Cosar M. Anterior approach to disc herniation with modified anterior microforaminotomy at C7-T2: technical note. Spine (Phila Pa 1976) 2009;34:1879-83.

3. Post NH, Cooper PR, Frempong-Boadu AK, Costa ME. Unique features of herniated discs at the cervicothoracic junction: clinical presentation, imaging, operative management, and outcome after anterior decompressive operation in 10 patients. Neurosurgery 2006;58:497-501.

4. Yamazaki S, Kokubun S, Ishii Y, Tanaka Y. Courses of cervical disc herniation causing myelopathy or radiculopathy: an analysis based on computed tomographic discograms. Spine (Phila Pa 1976) 2003;28:1171-5. 